\title{
SIGUIENDO EL RASTRO DEL ANIMAL AMBIVALENTE: LAS MANIFESTACIONES SINGULARES DEL PUERCO EN LA PRIMERA PARTE DEL QUIJOTE
}

\author{
Augustin Redondo \\ Université de la Sorbonne Nouvelle - CRES/LECEMO \\ auja.redondo@sfr.fr
}

$\mathrm{U}$

na tradición muy antigua indica que el cochino se nos parece mucho - como lo subraya un proverbio: «Si quieres ver cómo es tu cuerpo, mata un puerco» (Rodríguez Marín, 1926: 468b) — y que su carne es suculenta, según lo declaran dos refranes: «El cochino, mi consuelo» y «A puerco fresco y berenjenas, ¿quién tendrá las manos quedas?»(Correas, 2000: 262, 30). Del mismo modo, se ha podido considerar que este animal era particularmente noble, como lo ponen de relieve varias leyendas, y símbolo de fiereza y valentía, al no separar el puerco del puerco montés, es decir, del jabalí, lo que ha ocasionado una mitología de dicho animal. Pero otra tradición, que se enraíza especialmente en un pasado bíblico, nos dice que es un «animal inmundo» y hasta diabólico, símbolo de la mayoría de los vicios.

Lo que deseamos hacer en este trabajo es ver cómo los diversos aspectos evocados, en relación con el espacio y el momento histórico-social del Quijote, se manifiestan (muchas veces, con una tonalidad burlesca) en la primera parte de la obra, dejando para un trabajo posterior el estudio correspondiente en la segunda parte. Sin embargo, antes de seguir, tenemos que hacer dos observaciones.

En primer lugar, la palabra «cerdo», tan usual hoy en día, se desconoce en los siglos XVI y XVII, utilizándose casi siempre el término «puerco»y, asimismo, pero en menor medida, el de «cochino». La forma femenina «cerda» es únicamente la que se emplea, y ello, para designar «los pelos largos de crines y cola de cavallo o mula [...]. Solo los puercos están llenos de cerdas; éstas son cortas y duras» (Covarrubias, 1943: 408b). Añade el lexicógrafo que, para referirse a los puercos, se habla de «ganado de la cerda». 
Por otra parte, por los años en que se elabora el primer Quijote, se difunden varios textos que, de forma paradójica, hacen el encomio del puerco, a pesar de que a este se le considere como un animal soez, con una intención antijudaica y antimahometana (Redondo, en prensa). Estos textos pertenecen al género «jocoserio» y remiten tanto a la literatura llamada posteriormente «de cordel» como a los ejercicios de las academias o a la literatura de entretenimiento. Entre ellos, merece citarse una Obra maravillosa en alabanza del puerco, escrita en verso de romance, atribuida a un tal Francisco Marcos, y publicada en 1594, en un pliego suelto sevillano, reimprimiéndose luego varias veces en otras ciudades (en prensa) ${ }^{1}$. Lo mismo pasa con los Tercetos en loor del puerco, poema que Juan de Arjona leyó en la academia granadina de Pedro de Granada Venegas, entre 1598 y 1602, o con la Oda en loor del puerco que Agustín de Rojas insertó en su Viaje entretenido que salió de las prensas madrileñas en 1603 (en prensa).

No es extraño pues que el puerco esté presente en el primer Quijote, publicado en 1604-1605, esa obra paródica, que juega con la reversibilidad de los personajes y de los conceptos, esa obra en que las burlas se transforman en veras (Redondo, 1998).

Si nos atenemos al vocabulario de la primera parte, la palabra «puerco» solo aparece tres veces: dos en el capítulo 2, con referencia a actividades vinculadas a la crianza del animal (porquero y castrador) (Cervantes, 2015: I, 53, 58) ${ }^{2}$ y otra acerca de Dulcinea (I, 118).

De tal modo, estamos penetrando en la geografía y en la economía del Quijote. En efecto, la Mancha, esa tierra de llanuras y bosques, con algún monte en el Siglo de Oro, se dedicaba a la producción de cereales, vinos y aceite, pero también a la ganadería. Especialmente, por abundar las encinas y, por tanto, las bellotas, las manadas de puercos eran frecuentes, además de los cochinos «domésticos» criados en el ámbito de la mayoría de las casas, por lo menos en el campo.

Por ello, la presencia del porquero que recogía su rebaño, cuando don Quijote y Sancho se encaminan hacia la venta que fue la del armazón de caballería, nos sitúa en esa realidad evocada. Es lo que ocurre asimismo con la estancia en la venta de un castrador de puercos quien, a causa de su oficio, ha de trasladarse de un lugar a otro y de una manada a otra.

Pero hay que añadir algo más. Desde el capítulo 7, en que aparece la figura del campesino-escudero, el mismo universo porcino irrumpe en el texto. Es que «sancho» es también el nombre que se le da al cochino (aunque con menor frecuencia).

Es loque pone de realce Juan de Arjona en los Tercetos ... a los cuales nos hemos referido, ya que escribe: «Cochino, Puerco o Sancho, todo es uno»(Arjona, 1936: 132),

\footnotetext{
1 Nótese que, como ocurre muchas veces en esta literatura efímera, el nombre del presunto autor cambia en las nuevas ediciones.

2 Mencionamos la parte (I o II) y la página en la edición utilizada.
} 
lo que repite Agustín de Rojas en la Oda ... a la cual hemos aludido: «Pues Sancho, puerco o cochino, / todo es uno...» (Rojas, 1972: 473, v. 121)3.

Esa equiparación con el cochino se apoya en la observación de que este tiene un parentesco anatómico y fisiológico con el hombre, como lo había indicado ya Aristóteles y lo habían observado los médicos antiguos y medievales (Pastoureau, 1989: 245; 2015: 70, 87). Es lo que subraya el autor del pliego de finales del siglo XVI, al escribir: «[El puerco] en todo lo interior / es muy semejante al hombre» (Obra ..., 1974: 184-185). Esta relación se halla reforzada por una serie de creencias y relatos que estriban en un proceso de «metamorfosis», lo que permite el paso del hombre al cochino y recíprocamente.

Recuérdese ese pasaje de la Odisea en que la maga Circe transforma a los compañeros de Ulises en puercos, antes de que, cediendo a las amenazas de muerte proferidas por el héroe, les devuelva su naturaleza primera (Homero, 1997: X, 237-296). Esa transformación también la evoca posteriormente Ovidio en sus $\mathrm{Me}$ tamorfosis, tan leídas en el Siglo de Oro (1983: XV, 277-305).

La tradición de este parentesco entre el puerco y el hombre, con los cruces y las metamorfosis consiguientes se prolonga hasta la época actual, ya que, por ejemplo, en el apólogo de George Orwell de 1945, Rebelión en la granja, después de la rebeldía de los animales contra los granjeros, los cochinos desempeñan el papel que anteriormente les correspondía a los hombres, portándose de manera tan opresora como ellos y semejándose a ellos cada día más (Orwell, 1973).

Paralelamente, en una serie de cuentos orales del área mediterránea, relacionados con el de Pulgarcito, el ogro sigue apoderándose de los siete hermanos, pero su mujer los pone en la pocilga y los ceba para transformarlos en puercos y poder matarlos como tales (Fabre-Vassas, 1994: 106).

Por otra parte, una leyenda (vinculada a los orígenes de las familias nobles de los Porceles), muy arraigada en la zona catalana, en la región de Murcia y también en Provenza ${ }^{4}$, cuenta lo siguiente: una mujer muy pobre, acompañada de su numerosa prole, le había pedido una limosna a una dama que estaba encinta. Esta, con mucha altivez, se la había denegado, diciéndole además que no había que dar la vida a tantos críos cuando no se los podía alimentar. La pobre mujer, agraviada, le había pronosticado entonces a la señora que pariría como si fuera una puerca. Y en efecto da a luz una camada de hijos, con fisonomía más o menos porcina,

\footnotetext{
3 De ahora en adelante, solo mencionaremos el verso (o los versos) de la Oda. Por otra parte, recuérdese que el término «chancho» para designar al puerco ha venido a ser común en varios países de la América de habla española.

4 En Barcelona y Murcia, se trata del linaje de los Porceles, en Provenza del de Pourcelet (vinculado a la ciudad de Arles). Pero algo parecido ocurre con la estirpe del conde Diego Porcelos, fundador de Burgos. Nótese que una de las versiones de esta leyenda originó la comedia de Lope de Vega, Los Porceles de Murcia.
} 
conforme se dice en alguna versión de la leyenda (Amades, 1986: 46; Mistral, 1878; Fabre-Vassas, 1994: 56-57; Delpech, 1999: 247-249; etc.) ${ }^{5}$.

De tal modo, Sancho Panza viene a ser, en cierto modo, más que un primo (como diría Pastoureau), un hermano, o mejor dicho una personificación del puerco. Es preciso recordar también que, según la tradición platónica, y también judeocristiana, «el nombre es como imagen de la cosa de quien se dice» (León, 1959: 277-278), lo que viene a acentuar la presencia porcina del campesino. Es lo que delatan asimismo la gordura y pequeñez del escudero, su «voracidad», así como sus barbas «espesas, aborrascadas y mal puestas» (I, 256 ${ }^{6}$ a modo de cerdas porcunas. Sancho Panza aparece así, irónicamente, como un escudero rebajado, parodiado, porcino.

No se olvide, en efecto, la otra tradición que ve en el cochino un animal inmundo. De ahí que su consumo sea prohibido por la ley hebrea, conforme se indica en La Biblia (1569, Levítico, 9: 7; Deuteronomio, 14: 8), y asimismo por la ley musulmana, según se apunta en el Corán (1959: V, 3; VI, 146) ${ }^{7}$. Ese rechazo del puerco, considerado como un animal sucio y asqueroso, había provocado paralelamente entre los cristianos castellanos (aunque consumidores de cerdo) la costumbre de decir «con perdón», en el habla popular, cuando se pronunciaba el término «puerco» o «cochino», como se hacía cuando se mencionaba algo ruin. Es lo que ilustra el texto cervantino, si bien el autor utiliza festivamente la expresión, invirtiéndola, ya que apunta: «un porquero que andaba recogiendo de unos rastrojos una manada de puercos (que sin perdón así se llaman)...» (I, 53). Este deslustre también se le comunica al escudero pues lleva el nombre que en ocasiones se le da al cochino. Así, no extraña que don Quijote le recuerde posteriormente a su ayudante que fue porquero en otros tiempos, actividad desestimada a causa del contacto constante con los cerdos (II, 1.059).

\footnotetext{
La leyenda añade que en esos tiempos se pensaba que si una mujer tenía varios hijos de una vez es porque había tenido relaciones sexuales con varios hombres. Temerosa de lo que pensaría y haría su esposo, la dama había guardado solo uno de los vástagos, mandando a una criada que fuese a ahogar a los demás. Pero el marido había dado con la sirvienta. Esta le había contado que llevaba unos lechoncillos, aunque él había descubierto la verdad, entregando los niños a uno de sus granjeros para que los criase. Cuando ya fueron mayores, perdieron los rasgos porcinos y el padre los trajo a su mansión vestidos como el hijo que estaba en su casa. Resultaron todos semejantes, reconociendo la madre a sus vástagos, lo que provocó en ella remordimiento, vergüenza y congoja. En algunas versiones, la madre es duramente castigada por el padre y hasta muere; en otras, se halla perdonada. Lo que importa es que los hijos van a ser excelsos caballeros, cumpliendo muchas hazañas y teniendo amplia descendencia nobiliaria. Lo que era negativo (el parto múltiple) se ha invertido ahora, transformándose en algo muy positivo: la feracidad, el dinamismo y el desarrollo del linaje. Por ello, el blasón de los Porceles encerraba un puerco montés. Ver también Delpech (1999: 246-247).

6 Sobre las barbas sanchescas, ver Redondo (2011: 143-144).

7 El primer número remite a la sura y el segundo al versículo.
} 
Sea lo que fuere, el puerco, aunque el vocablo aparezca muy poco en la primera parte del Quijote, se halla presente metafóricamente a lo largo del texto con el personaje del escudero.

A primera vista, el héroe del relato, el hidalgo manchego, no parece pertenecer de por sí al universo porcino. Sin embargo, desde el principio de la obra, se precisa que comía la mayoría de los días una «olla de algo más vaca que ternera» $(I, 38)$. Y sabido es que no existía olla sin el consabido tocino, como lo indica el refrán recogido por Sebastián de Horozco antes de 1580: «Ni olla sin tocino, ni sermón sin agustino» (1986: 419, n. ${ }^{\circ}$ 2.021) y lo corrobora el pliego de 1594 ya citado, en alabanza del puerco: "Cualquier olla o guisado / que se tiene de guisar / está bien experimentado / para comer buen bocado / que tocino ha de llevar» (Obra ..., 1974: 71-75). Asimismo, los sábados tomaba «duelos y quebrantos», lo que, según la interpretación generalmente admitida, desde que la formuló Francisco Rodríguez Marín en 1914, apoyándose en varios textos y en uno decisivo de Calderón, significaba que le preparaban huevos con torreznos, o sea, con tocino frito (Rodríguez Marín, 1949). Efectivamente, es preciso recordar que la carne de cerdo, bajo sus diversas formas de preparación y conservación, estaba muy presente en la alimentación de la población, especialmente en zonas rurales, como la manchega, donde se criaban muchos cochinos. Es que, desde tiempos antiguos, la carne de puerco montés o doméstico era muy apetecida. Así griegos y latinos gustaban mucho de ella, diciendo Plinio, por ejemplo, que dicha carne tenía cincuenta sabores diferentes (Pastoureau, 1989: 241). Lo mismo ha ocurrido en épocas posteriores, en particular a lo largo de la Edad Media y de la época moderna.

Alonso Quijano se inserta pues perfectamente en esa sociedad manchega comedora de carne de cerdo.

Es necesario añadir que, en el capítulo 9, en uno de los cartapacios comprados en «el alcaná de Toledo», se encontraba un libro con una significativa mención marginal: «Esta Dulcinea del Toboso, tantas veces en esta historia referida, dicen que tuvo la mejor mano para salar puercos que otra mujer en toda la Mancha» (I, 118). Es decir que Aldonza Lorenzo, alias Dulcinea del Toboso, la mujer a partir de la cual don Quijote ha fraguado a la dama amada, se halla vinculada al mundo de los puercos, ya que es una experta en el arte de salar los cochinos después de la matanza. Se trata de una degradación evidente y burlesca que rebaja a la dama y a los sueños amorosos del protagonista; este se halla también rebajado, al estar unido así al universo porcuno.

Y ahora aflora un problema que Américo Castro y sus seguidores han barajado varias veces. En efecto, para Castro, sobre el trasfondo de su concepción del conflicto entre las castas, la alimentación de don Quijote los sábados (huevos con torreznos) se halla evocada según la visión de los cristianos nuevos («duelos y quebrantos», a causa de la necesidad de comer tocino), mientras que la de los 
cristianos viejos se traduciría por la expresión equivalente («la merced de Dios») (Castro, 1974: 26-27). Así se pondría de relieve la línea de separación entre cristianos nuevos y cristianos viejos o, dicho de otra manera, entre tocinófobos y tocinófilos (Castro, 1974: 27 y ss.).

Si bien es verdad que esta oposición existe (Redondo, en prensa) y si Sancho Panza, por todo lo que hemos señalado anteriormente, por su afición al tocino y por su afirmación repetida de ser cristiano viejo (I, 255; I, 598) no puede ser sino tocinófilo, ¿qué pasa con don Quijote? Sutilmente, don Américo indica: «Cervantes - un zorro socarrón y genial - se abstiene de precisar si el comer tocino era "duelo y quebranto" para el futuro don Quijote» (Castro, 1974: 26). No obstante, el razonamiento de Castro conduciría lógicamente a incluir al héroe entre esos «hidalgos manchados» que existían en la Mancha con alguna frecuencia (Redondo, 1998: 227-228), como lo han hecho varios de los discípulos del maestro. Pero Cervantes, como siempre, hila muy fino y con ironía, de modo que la cosa queda en el aire.

Por otra parte, hay que tener presente la evocación de la edad dorada hecha por don Quijote cuando está con los cabreros (I, 133-134). Dicha evocación se parece mucho en lo esencial a la que nos han legado los antiguos, tanto Ovidio (1983: I, 89 y ss.; XV, 96 y ss.) como Virgilio (2012: I, 125 y ss.) u Horacio (1990: XVI, 45 y ss.), por ejemplo. Se trata de un verdadero paraíso terrenal, de esa época de Saturno, en que la naturaleza le ofrecía al hombre, con prodigalidad, todo lo que necesitaba sin tener que trabajar. En esas ideaciones de la edad dorada no faltan los detalles de las bellotas, del agua pura, de la miel y de la leche que brindaban las cabras a los humanos. La presencia de los cabreros, la carne y los quesos cabrunos, en un lugar agreste, pero sobre todo del puñado de bellotas que el caballero contempla, son un incentivo para que se rememore y exalte ante su auditorio la amenidad de la edad de oro.

Lo que llama la atención es que por los mismos años en que se elabora el Quijote de 1605, el autor del pliego suelto citado varias veces y el humanista Juan de Arjona, en sus respectivas alabanzas del puerco, introducen también una evocación de la edad dorada. En el primer caso, se indica «que en aquella edad primera / las bellotas y agua fría / [eran] principal mantenimiento» (Obra ..., 1974: 63-65). Y las bellotas no pueden sino remitir a los cochinos: «en este tiempo presente / de los puercos solamente / vemos ser muy estimadas [las bellotas]» (Obra ..., 1974: 69-70), lo que le permite al autor valorar al animal, muy parecido al hombre de aquellos tiempos primeros. Arjona va por otro camino: él parte de la premisa de que el cerdo no puede faltar en los banquetes y fiestas, añadiendo: «en aquella primera edad dichosa, / del puerco se comió por gran regalo» (1936: 175-176), lo que le lleva a delinear diversas características encantadoras de la edad de oro, acabando por la siguiente: «Sólo el puerco en las fiestas principales / augmentaba, 
muriendo, el alegría, / más que el son de las flautas y atabales» (Obra ..., 1974: 196-198). Esto plantea un problema, porque en las evocaciones clásicas de la edad dorada no se habla del cochino. Queda claro que Arguijo ha vinculado la primera edad, la de Saturno, a las Saturnales romanas (Guittard, 2008), esa época «carnavalesca» de inversiones sociales, igualdad, ocio, diversiones, comidas opíparas y fiestas continuas del mes de diciembre (Macrobio, 2010) ${ }^{8}$, especie de reminiscencia de la prodigalidad y ausencia de trabajo de los tiempos primeros. Y precisamente, en las Saturnales, se sacrificaba un puerco de dos años y la carne de cerdo era el manjar predilecto de esa época, especialmente el porcus troianus (panza de cerdo rellena de salchichas, morcillas, pollo y legumbres) (Poccetti, 2009: 136-140).

De este modo, hubiera sido natural que el puñado de bellotas, con la evocación de la edad de oro, hubiera conducido a don Quijote a hablar del puerco y de su alimento favorito, como lo hacía el autor del pliego. De la misma manera, en el marco manchego, se pudiera haber situado el episodio entre porqueros, en vez de entre cabreros, y se pudiera haber comido carne de cerdo, dando la posibilidad asimismo al puñado de bellotas de evocar la edad primera. Sin embargo, el desmérito unido al puerco, animal ambivalente, y al porquero ha llevado a rechazar tal perspectiva.

A fin de cuentas, don Quijote, ¿tocinófobo?

Al revés, no se olvide que el héroe ha de referirse a su calidad de «hijodalgo de solar conocido» (I, 254) y a su entronque con el linaje de los «valientes españoles Pedro Barba y Gutierre Quijada, de cuya alcurnia yo deciendo por línea recta de varón» $(\mathrm{I}, 620)$, aunque esta referencia cobre una tonalidad más o menos humorística (Redondo, 1998: 213-214). Esto lo situaría más bien entre los cristianos viejos, o sea entre los tocinófilos, tanto más que el manchego está relacionado con el contexto porcuno de la mujer amada y además tiene él también una peculiaridad significativa.

Efectivamente, en la burla ideada por el cura y Dorotea, esta, que hace de princesa Micomicona, viene a pedir auxilio al héroe contra su tío el gigante Pandafilardo que le ha usurpado el reino y quiere obligarla a casarse con él (I, 380-382). Según la profecía del padre de la princesa, Tinacrio el Sabidor, el héroe que pueda realizar la hazaña de matar al usurpador ha de ser un caballero andante «que en el lado derecho, debajo del hombro izquierdo, o por allí junto, [ha] de tener un lunar pardo con ciertos cabellos a manera de cerdas» (I, 382). Se asiste entonces a una escena burlesca en que don Quijote quiere desvestirse para comprobar que lleva la marca indicada, pero Sancho se adelanta para afirmar que su señor tiene tal lunar

8 Más que nada, el texto de Macrobio viene a ser un banquete dialogado e intelectual, en que se barajan numerosos temas, especialmente de índole religiosa y literaria. 
en mitad del espinazo. La burlona Dorotea indica entonces que poco importa el sitio, ya que existe la señal.

El tema de la marca (el lunar en bastantes casos), que permite reconocer al héroe elegido y encubierto (con un recorrido que con frecuencia le conduce al trono), se repite en muchos escritos proféticos, en la literatura escrita - libros de caballerías, romancero, novela- y también oral (Delpech, 1990: 38-47). Es lo que pasa en este episodio del Quijote (Redondo, 2011: 74-76).

Lo que nos interesa aquí directamente es la expresión que resulta algo ambigua: «lunar con cabellos a manera de cerdas». Es que, la primera parte hubiera bastado: «lunar con cabellos». Lo añadido debe de corresponder a la perspectiva burlesca adoptada, si bien es necesario aclarar el significado. En efecto, puede tratarse de las crines del caballo, por ejemplo, como lo apunta Covarrubias, o asimismo referirse a las cerdas del puerco, como lo indica también el lexicógrafo (1943: 408b). Dada la orientación jocosa del pasaje, la segunda interpretación resulta la más adecuada. Pero hay otra razón. En muchas partes, ese lunar con pelos no solo puede ser señal de una forma primitiva de marca principesca y real (Delpech, 1990: 44) sino también indicio de la influencia porcina, pues se considera que el puerco, doméstico o montés, es responsable, por simple contacto, efectivo o soñado, del nevus peloso (Jaberg, 1957: 325-328; Fabre-Vassas, 1995: 55-57).

Esta marca con pelos transforma al manchego en un elegido encubierto, cuyo destino, unido a la profecía de finales de la primera parte de la obra, es entroncar con la realeza y venir a ser fundador de una estirpe real (Redondo, 2011: 75-79). Dicha marca no puede sino hacer pensar en la que llevaba el infante don Fernando de la Cerda, hijo del rey Alfonso X el Sabio. Pues una leyenda muy esparcida y transmitida además por diversas crónicas, indicaba que ese príncipe «nació con un lunar en la espalda de donde le colgaba un cabello largo y gruesso, como cerda» (Covarrubias, 1943: 409b). Por ello, se le había llamado don Fernando de la Cerda, siendo el fundador de la ilustre casa De la Cerda, la de los duques de Medinaceli. Y precisamente, don Quijote, al hablar de la estirpe de Dulcinea del Toboso ante Vivaldo, evoca los insignes linajes de España y entre ellos cita el de «los Cerdas» (I, 155). Así que el héroe manchego, con una perspectiva jocosa, podría venir a ser otro don Fernando de la Cerda...

Por otra parte, la relación del linaje De la Cerda con el universo porcuno debía de hacerse más de una vez dado lo que acabamos de exponer. El caso es que el autor del pliego en alabanza del puerco, que sale a finales del siglo xvI, no vacila en jugar con la palabra «cerda», aludiendo tanto al ganado de la cerda como a la Casa de la Cerda: «Las personas estimadas / de noble suelo y simiento / merecen ser veneradas / y de todos alabadas / por su gran merescimiento. / Del puerco y de sus favores / esta gracia se me acuerda / quél y sus progenitores / son dignos de mil loores / por ser de los de la cerda» (Obra ..., 1974: 141-150). Paralelamente, 
en su oda de 1603, en loor del cochino, Agustín de Rojas evoca «el animal más noble» (1972: 69) y habla del «puerco hidalgo» (Obra..., 1974: 192).

En resumidas cuentas, y con referencia a las categorías de Américo Castro, ¿hay que incluir al caballero manchego entre los tocinófilos?

Las cosas no son tan sencillas. Don Quijote es un héroe ambivalente, en consonancia con lo que es la obra cervantina: lo que domina en ella, es la ambivalencia, la reversibilidad de los personajes y de las situaciones...

Lo que sí se puede decir es que en el texto se ponen en tela de juicio la ostentación de cristiandad vieja esgrimida como señal de hidalguía y los prejuicios de limpieza de sangre (Redondo, 1998: 76).

Pero volvamos a Sancho el porcino y a lo que su nombre sugiere.

Una tradición, arraigada ya entre los antiguos, relaciona al puerco con la realeza, como lo demuestra, en la mitología griega, el caso de Tideo. La madre de este, Peribea, fue seducida por el rey de Calidón, Eneo, y abandonada por él cuando estaba encinta. Se refugió entonces entre unos porqueros, de modo que el hijo que tuvo, Tideo, creció entre ellos y los cochinos medio salvajes, llevando un pellejo de puerco montés. Algunas fuentes dicen que dicho pellejo fue el del enorme y devastador jabalí de Calidón eliminado por Meleagro. Al alcanzar la edad varonil, el joven mató al hermano de Eneo y fue desterrado, llegando a Argos al mismo tiempo que Polinices quien estaba cubierto con una piel de león. El oráculo de Apolo le había profetizado al rey de Argos, Adrasto, que tendría que casar a sus dos hijas, la una con un león y la otra con un puerco montés. Adrasto, al ver a los dos jóvenes, consideró que correspondían a los designados por el oráculo de manera que Tideo y Polinices vinieron a ser sus yernos, prometiéndoles el rey que les ayudaría a recuperar el trono respectivamente de Calidón y de Tebas (Picard, 1958: 465).

A este mito se refiere Juan de Arjona cuando, en su loor del puerco, empieza por evocar los despojos del «bravo puerco»: «Deste pellejo se adornó Tideo» (1936: 274). Añade luego, de manera significativa: «Cuéntase que el oráculo de Apolo / de Argos el Rey, para casar su hija, / [...] rogó mucho que un príncipe le elija, / y Apolo, importunado, ha respondido / [...] que diese a su hija por marido / [...] un príncipe que Puerco hubiese sido» (1936: 277-285). Y prosigue: «el gran Tideo a su palacio llega / cubierto de los célebres despojos / [...] De Apolo vio [el Rey] el oráculo cumplido, / conociendo que aquel era el esposo / que a su hija han los hados prometido» (1936: 292-300).

Asimismo, a nivel popular, el tema del «rey puerco» corre a través de un cuento del área mediterránea, ya que se conoce en la península y las islas italianas, en una parte de Francia y hasta en Rumania (Fabre-Vassas, 1994: 53-54). Cuenta lo siguiente: una pareja real no podía engendrar y la reina desea tener un hijo, aunque fuera un animal. Las tres hadas que acogen su petición pronostican que ha de dar la vida a un príncipe con las particularidades de un lechón, el cual no podría 
ser desencantado sino después de haberse casado tres veces. La reina da a luz efectivamente a un cochinillo, mimado por los padres, el cual crece, consiguiendo el habla, sin dejar de tener los modales de un puerco, revolcándose en el lodo y oliendo mal. Cuando llega a la edad adecuada, le dice a su madre que quiere casarse con una de las tres hijas hermosísimas de una pobre mujer. La boda se verifica dos veces con las dos hermanas mayores, quienes sienten una profunda aversión por ese repugnante marido. Quieren pues apuñalarlo por la noche, pero se adelanta él a hacerlo. Llega el casamiento con la hermana menor, la cual le recibe amorosamente, se acuesta con él y dará la vida a un niño hermoso. El príncipe puerco le descubre su secreto a la amada esposa: por la noche, se quita el pellejo de cerdo y se convierte en un hermoso joven. Los reyes, avisados por la nuera, se apoderan por la noche de la piel de cochino y la queman, deshaciendo el encanto. La hermosa pareja sube al trono, gobernando con benevolencia y justicia para el bien de todos los súbditos, pero el nuevo soberano quiere que le llamen «el rey puerco» (Straparola, 2017: 309-315; Fabre-Vassas, 1994: 53-55; Delpech, 1999: 250).

Este cuento tiene mucho que ver con el parentesco ya evocado entre el hombre y el cochino, y con la feracidad de la puerca que metafóricamente sustituye a la reina, así como con la metamorfosis amorosa, de tonalidad iniciática, simbolizada por el acto carnal de los jóvenes y la quema del pellejo. Por lo demás, el cuento corresponde al tipo 413A del catálogo de Aarne y Thompson (1973) y no es más que una de las modalidades del tema de «la bella y la bestia» que figura en el mismo repertorio (1973: 425A). Es de notar que el cuento del rey puerco se conoce de otra forma en el área lingüística del castellano, del catalán y del portugués, tratándose del cuento de «El lagarto de las siete camisas» (Camarena y Chevalier, 1995: 241-246). El lagarto desempeña el mismo papel que el cerdo, el del monstruo animal como esposo, con los mismos motivos (la pareja real, la infertilidad, el engendro monstruoso, los tres casamientos, la metamorfosis amorosa con la tercera mujer, la quema de las siete pieles de lagarto, el engendro del hijo) si bien el cuento tiene además una segunda parte.

No obstante, con referencia al tema del cochino, hay que añadir que el cuento del rey puerco se recoge por primera vez en una versión escrita a mediados del siglo XVI, en la primera parte de Le piacevoli notti del italiano Gianfrancesco Straparola ${ }^{9}$, conjunto de novelas que siguen el modelo del Decamerón de Boccaccio, alcanzando amplia difusión en Italia.

El texto que nos interesa es la primera fable de la segunda noche (Straparola, 1972: 474-478). La primera parte de la obra de Straparola fue traducida al castellano por el baezano Francisco Truchado. Se publicó la traducción en 1576 bajo el título de Honesto y agradable entretenimiento de damas y galanes, con algunos

$9 \quad$ La primera parte se publica en 1550 y la segunda en 1553. 
arreglos, modificaciones, supresiones e introducción de algún que otro texto, deseando Truchado eliminar lo que fuese demasiado erótico para evitar la censura inquisitorial (Federici, 2014; Coppola, 2017). El texto tuvo buena acogida en España pues entre 1576 y 1612 gozó esa primera parte traducida de cinco ediciones y lo que es de notar es que el cuento del rey puerco figura en todas ellas, como en las italianas.

Cervantes debió de conocer el mito de Tideo y, además, de modo intermitente, vivió en Italia durante varios años, entre 1569 y 1575, y allá pudo oír el cuento mencionado. Por fin, según parece, el autor del Quijote había leído a Straparola, sea en italiano sea en castellano (Coppola, 2013: 373).

Es pues probable que el cuento del rey puerco haya contribuido a hacer cuajar el deseo de Sancho de venir a ser gobernador de una ínsula (I, 99-100, 101; I, 123; I, 645) y hasta la ilusión prodigiosa que baraja de transformarse en soberano de algún reino (I, 102; I, 397). Recuérdese, por ejemplo, lo que le dice don Quijote a su escudero, dándole esperanzas de ser conde o marqués o todavía más: «bien podría ser que antes de seis días ganase yo tal reino, que tuviese otros a él adherentes que viniesen de molde para coronarte de rey de uno dellos» (I, 102). A lo cual, el ayudante contesta: «De esa manera, si yo fuese rey por algún milagro de los que vuestra merced dice...» $(\mathrm{I}, 102)$. Parece que estamos en un cuento maravilloso, como el del rey cerdo.

Pero hay que añadir otros datos.

En relación con la tradición del rey puerco, es necesario tener presente que Sancho ha sido nombre de reyes. Es lo que subrayan dos de los autores que, a finales del siglo XVI y principios del siglo XVII, escriben en alabanza del cochino. Así, Juan de Arjona indica: «Este animal [el puerco] con quien el vientre ensancho, / a más de un rey legítimo de España, / ha dado el noble nombre de don Sancho» (1936: 124-126). Y lo mismo repite Agustín de Rojas: «Este gentil animal, / que ha dado, cierto sabemos, / a más de algún rey de España, / su natural nombre mesmo» (1972: 109-112).

Entre todos los soberanos de León, Navarra, Aragón y Castilla que, en la época medieval, llevaron este nombre, tal vez sea útil rememorarse a Sancho Abarca (es decir a Sancho Garcés II, rey de Pamplona, confundido hasta bien entrado el siglo XVI con su abuelo de mismo nombre). Una leyenda muy conocida decía que su padre, al pelear contra los moros, había caído en una asechanza cuando iba acompañado por su esposa, la cual estaba encinta y cerca de dar a luz. Fueron matados por los moros y la reina recibió una lanzada en el vientre. Por la llaga, empezó a salir la mano del hijo. Un noble de las montañas salvó al niño y este se crio entre los rústicos, llevando rudimentarias alpargatas llamadas abarcas. Pero rápidamente demostró su valor y su capacidad organizativa, luchando contra los moros, al frente de sus compañeros. Gracias a sus dotes y al testimonio del noble 
que le había recogido, fue reconocido como príncipe, reinando bajo el nombre de Sancho Abarca (Cañada Juste, 2012: 84-85).

Esta leyenda, utilizada hasta por los cronistas del siglo XVI, hace pensar en el mito de Tideo. No obstante, a estas alturas, el que nos interesa es el caso de Sancho Abarca, criado entre rústicos, que viene a ser soberano de Pamplona, de modo que otro Sancho campesino, el carnavalesco Sancho Panza (Redondo, 1998: 195 y ss.), bien puede llegar a ser rey, no solo rey de los cochinos (Caro Baroja, 1965: 331-333), sino también rey de una ínsula, aunque no sea más que de manera efímera y de forma jocosa.

Por otro lado, por tierras de Castilla, corrían los romances viejos del rey don Sancho, matado por Vellido Dolfos, que el escudero de don Quijote no podía ignorar (Menéndez Pidal, 1968: I, 201-201; I, 216-217; II, 175; Romancero, 1993: 123-128), lo que viene a reforzar lo indicado ya.

De ahí que la profecía burlesca del final de la primera parte del Quijote no pueda sino enaltecer el ánimo de Sancho pues la voz vaticinadora, que parece salir del cielo, le pronostica un futuro exaltador: «Te verás tan alto y tan sublimado, que no te conozcas, y no saldrán defraudadas las promesas que te ha hecho tu buen señor» (I, 588-589). Es decir que, al tomar en serio la profecía, el escudero cobra grandes esperanzas de ver colmados sus sueños de engrandecimiento, lo que implica una tercera salida en compañía del caballero.

Al término de este trabajo y gracias al enfoque interdisciplinar adoptado (historia cultural, antropología, análisis literario), se puede decir que el puerco, ese animal ambivalente, percibido como positivo o/y negativo en el área mediterránea, ha desempeñado un papel incuestionable en la elaboración de la primera parte de la obra cervantina. Es lo que ha puesto de relieve el examen del contexto del Quijote, de los personajes de Sancho, don Quijote y Dulcinea del Toboso, así como el de algunos trozos significativos del texto. 


\section{BIBLIOGRAFÍA}

Aarne, Antti and Stith Thompson (1973). The Types of the Folktale. A Classification and Bibliography. Helsinki: Academia Scientiarum Fennica.

Amades, Joan (1986). Les millors llegendes populars. Barcelona: Selecta.

ARJonA, Juan de (1936 [1598-1602]). Tercetos en loor del puerco. En Francisco Rodríguez Marín (ed.), «Dos poemitas de Juan de Arjona leídos en la Academia granadina de D. Pedro de Granada Venegas (1598-1602)». Boletín de la Real Academia Española, 23, pp. 339-380. Los Tercetos están en las pp. 349-358.

Biblia, que es los sacros libros del Viejo y Nuevo Testamento, La (1569). Casiodoro de Reina (trad.). Madrid: Talleres de Mateu-Cromo [ed. facsímil, 1970].

Camarena, Julio y Maxime Chevalier (1995). Catálogo tipológico del cuento folklórico español. Cuentos maravillosos. Madrid: Gredos.

Cañada Juste, Alberto (2012). «¿Quién fue Sancho Abarca?». Príncipe de Viana, 73, pp. 79-132.

Caro Baroja, Julio (1965). El carnaval (Análisis histórico-cultural). Madrid: Taurus.

CAStro, Américo (1974). Cervantes y los casticismos españoles. Madrid: Alianza Editorial / Alfaguara.

Cervantes, Miguel de (2015). Don Quijote de la Mancha [1605-1615]. Francisco Rico (coord.). Madrid: Real Academia Española.

Coppola, Leonardo (2013). «Prolegómenos a la edición del Honesto y agradable entretenimiento de damas y galanes». En Alain Bègue y Emma Herrán Alonso (eds.), Pictivia Aurea. Actas del IX Congreso de la Asociación Internacional «Siglo de Oro». Toulouse: Presses Universitaires du Mirail, pp. 367-374.

Coppola, Leonardo (2017). «Truchado, Le piacevoli notti: la naturalización hispánica de un texto ad usum nationis». Artifara, 17, pp. 99-114.

Coran, Le (1959). Muhammad Hamidullah (trad.). Paris: Le Club Français du Livre.

CORREAS, Gonzalo (2000 [1627]). Vocabulario de refranes y frases proverbiales. Louis Combet (ed.), con revisión de Robert Jammes y Maïté Mir-Andreu. Madrid: Castalia.

Covarrubias, Sebastián de (1943 [1611]). Tesoro de la lengua castellana o española. Martín de Riquer (ed.). Barcelona: Horta.

DelPECH, François (1990). «Les marques de naissance: physiognomonie, signature magique et charisme souverain». En Augustin Redondo (ed.), Le corps dans la société espagnole des XVIe et XVIIe siècles. Paris: Publications de la Sorbonne, pp. 27-49.

DelPeCH, François (1999). «Légendes généalogiques et mythologie porcine». En Philippe Walter (coord.), Mythologies du porc. Grenoble: Millon, pp. 239-283.

FaBre-VASSAS, Claudine (1994). La bête singulière. Les juifs, les chrétiens et le cochon. Paris: Gallimard.

FEDERICCI, Marco (2014). «La huella de Boccaccio en el Renacimiento español y la recepción de Le piacevoli notti de Straparola». Dicenda. Cuadernos de Filología Hispánica, 32, pp. 95-111.

GuitTARD, Charles (2003). «Les Saturnales à Rome: du mythe de l'Âge d'Or au banquet de décembre». Pallas, 61, pp. 219-236.

Homero (1997). Odisea. José Manuel Pabón (trad.). Barcelona: Planeta De Agostini. 
Horacio (1990). «Epodos». En Odas y Epodos. Manuel Fernández-Galiano y Vicente Cristóbal (trad. y ed.). Madrid: Cátedra.

Horozco, Sebastián de (1986 [entre 1558 y 1580]). Teatro Universal de proverbios. José Luis Alonso Hernández (ed.). Salamanca: Universidad de Groningen / Universidad de Salamanca.

JABERG, Karl (1957). «The bigmark in folk belief, language, literature and fashion». Romance Philology, 10-4, pp. 307-342.

León, fray Luis de (1959). «Los nombres de Cristo». En Obras completas castellanas. Félix García (ed.). Madrid: Biblioteca de Autores Cristianos, pp. 385-790.

Macrobio (2010). Saturnales. Fernando Navarro Antolín (trad. y ed.). Madrid: Gredos.

MenÉndez PidAl, Ramón (1968). Romancero hispánico. Madrid: Espasa Calpe.

Mistral, Frédéric (1878). «Li Pourcelet». L'Armana Provençau, 24, pp. 57-59.

Obra maravillosa en alabança del puerco, con un villancico en su loor y un Romance de los Romanos. Hecho por Francisco Marcos (1594). Sevilla: Fernando Lara [reproducción en facsímil en Pliegos poéticos españoles de la Biblioteca Universitaria de Gotinga (1974). María Cruz García de Enterría (estudio). Madrid: Joyas Bibliográficas].

Orwel, George (1973). Rebelión en la granja. Rafael Abella (trad.). Barcelona: Destino. Ovidio (1983). Metamorfosis. Antonio Ruiz de Elvira (trad. y ed.). Barcelona: Bruguera.

Pastoureau, Michel (1989). «L'homme et le porc: une histoire symbolique». En Couleurs, images, symboles. Études d'histoire et d'anthropologie. Paris: Le Léopard d'Or, pp. 237-282.

Pastoureau, Michel (2015). El cerdo. Historia de un primo malquerido. José Miguel Parra (trad.). Almería: Confluencias.

PicARD, Charles (1958). Dictionnaire de la mythologie grecque et romaine. Paris: Presses Universitaires de France.

Poccetti, Paolo (2009). «Un animal au centre du monde. Le cochon dans l'Antiquité italique et romaine». Schedae, 8: 1, pp. 125-142.

Redondo, Augustin (1998). Otra manera de leer el «Quijote». Historia, tradiciones culturales y literatura. Madrid: Castalia.

Redondo, Augustin (2011). En busca del «Quijote» desde otra orilla. Alcalá de Henares: Centro de Estudios Cervantinos.

REDONDO, Augustin (en prensa). «Un caso específico de antijudaismo y antimahometismo a finales del siglo XVI y principios del siglo XVII: las poesías en alabanza del puerco». En Ruth Fine et alii (eds.). Actas del XX Congreso de la Asociación Internacional de Hispanistas. Jerusalén: Universidad Hebrea de Jerusalén.

Rodríguez Marín, Francisco (1926). Más de 21.000 refranes castellanos no contenidos en la copiosa colección del Maestro Gonzalo Correas. Madrid: Tipografía de la Revista de Archivos, Bibliotecas y Museos.

Rodríguez Marín, Francisco (1949). «Duelos y quebrantos». En apéndice a su ed. del Quijote. Madrid: Atlas, t. 9, pp. 85-114.

Rojas Villandrado, Agustín de (1972 [1603]). «Oda en loor del puerco». En Viaje entretenido. Jean-Pierre Ressot (ed.). Madrid: Castalia, pp. 469-478.

Romancero (1993). Giuseppe Di Stefano (ed.). Madrid: Taurus. 
Straparola, Gianfrancesco (1972 [1550]). «Le piaccevoli notti». En Novellieri del Cinquecento, Milano: Ricciardi, vol. 24, I, pp. 457-643.

Straparola, Gianfrancesco (2017 [1576]). Honesto y agradable entretenimiento de damas y galanes. Francisco Truchado (trad.). Lemir, 21, pp. 251-448.

VIRGilio (2000). Bucólicas. Vicente Cristóbal (trad. y ed.). Madrid: Cátedra.

Virgilio (2012). Geórgicas. Jaime Velázquez (trad. y ed.). Madrid: Cátedra.

Recibido: 21/03/2021

Aceptado: 13/05/2021 


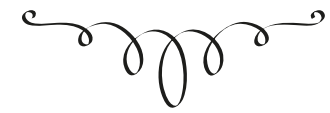

SiguiENDO EL RASTRO DEL ANIMAL AMBIVALENTE: LAS MANIFESTACIONES SINGULARES DEL PUERCO EN LA PRIMERA PARTE DEL QUIJOTE

RESUMEN: En este trabajo, en que se aúnan orientaciones de historia cultural, antropología y análisis literario, se examinan las huellas positivas y negativas que el puerco, ese animal ambivalente y tan importante en el área mediterránea, ha dejado en la elaboración de la primera parte del Quijote. Se pone el énfasis en los tres personajes principales de la obra (Sancho Panza, don Quijote y Dulcinea del Toboso), especialmente en los dos primeros, así como en algunos trozos significativos del texto.

Palabras clave: Puerco, Quijote cervantino, Sancho Panza, don Quijote, Dulcinea del Toboso, historia cultural, antropología, literatura.

Following THE TRACE OF THE AMBIVALENT ANIMAL: THE SINGULAR MANIFESTATIONS OF THE PIG IN THE FIRST PART OF THE DON QUIXOTE

ABSTRACT: In this work, where cultural history, anthropology and literary analysis are combined, we examine the positive and negative traces that the pig, this ambivalent animal and so important in the Mediterranean area, has left in the elaboration of the first part of Don Quixote. The focus is on the three main characters of the work (Sancho Pansa, Don Quixote and Dulcinea del Toboso), especially on the first two, as well as on some significant passages of the text.

Keywords: Pig, Cervantine Don Quixote, Sancho Pansa, Don Quixote, Dulcinea of Toboso, Cultural history, Anthropology, Literature. 